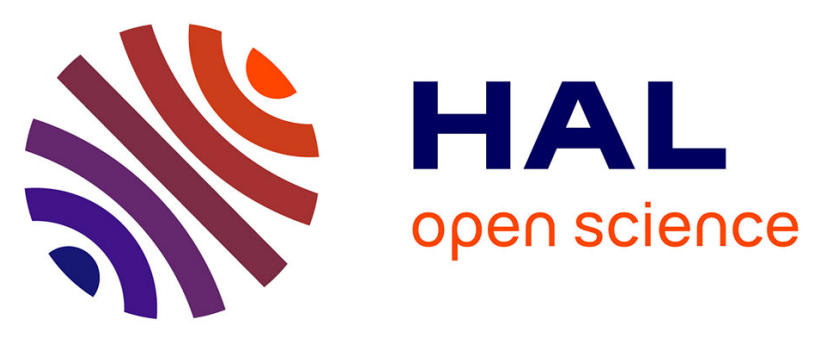

\title{
LE JUSTICIA D'ARAGON DANS QUELQUES CHRONIQUES DE LA COURONNE D'ARAGON AUX XIVE ET XVE SIÈCLES : ENTRE FICTION JURIDIQUE ET REPRÉSENTATION DU POUVOIR ROYAL
}

Sophie Hirel-Wouts

\section{To cite this version:}

Sophie Hirel-Wouts. LE JUSTICIA D'ARAGON DANS QUELQUES CHRONIQUES DE LA COURONNE D'ARAGON AUX XIVE ET XVE SIÈCLES: ENTRE FICTION JURIDIQUE ET REPRÉSENTATION DU POUVOIR ROYAL. Cahiers d'Etudes Hispaniques Médiévales, 2006, 29, p. 277-300. halshs-00262313

\section{HAL Id: halshs-00262313 \\ https://shs.hal.science/halshs-00262313}

Submitted on 11 Mar 2008

HAL is a multi-disciplinary open access archive for the deposit and dissemination of scientific research documents, whether they are published or not. The documents may come from teaching and research institutions in France or abroad, or from public or private research centers.
L'archive ouverte pluridisciplinaire HAL, est destinée au dépôt et à la diffusion de documents scientifiques de niveau recherche, publiés ou non, émanant des établissements d'enseignement et de recherche français ou étrangers, des laboratoires publics ou privés. 


\section{LE JUSTICIA D'ARAGON DANS QUELQUES CHRONIQUES DE LA COURONNE D'ARAGON AUX XIV ${ }^{\mathrm{E}}$ ET $\mathrm{XV}^{\mathrm{E}}$ SIÈCLES : ENTRE FICTION JURIDIQUE ET REPRÉSENTATION DU POUVOIR ROYAL}

Le Justicia d'Aragon est une figure majeure de l'imaginaire politique aragonais. Rendu populaire en 1591, suite à l'assassinat du jeune Justicia Lanuza par Philippe II, puis récupéré et exalté à la fin du $\mathrm{XVIII}^{\mathrm{e}}$ siècle par les libéraux et nationalistes espagnols, le personnage est majoritairement perçu depuis quatre siècles comme le symbole des libertés inaliénables du royaume d'Aragon face à l'autoritarisme castillan ${ }^{1}$. Ce «prisme de $1591 »$ a longtemps occulté tout ce qui était antérieur au $\mathrm{XVI}^{\mathrm{e}}$ siècle dans l'histoire de la magistrature, alors même que les textes médiévaux - et notamment la production historiographique de l'Est péninsulaire - portent sur le sujet de nombreux témoignages et permettent d'appréhender la signification attribuée à la charge dès ses origines ${ }^{2}$. Né en 1265 de la nécessité qu'il y ait un judex medius, un juge médiateur entre le roi et les grands du royaume, le Justicia d'Aragon est en effet plusieurs fois évoqué dans les chroniques de Couronne d'Aragon : il y apparaît d'abord comme simple fonctionnaire de la justice royale, notamment dans les "quatre grandes chroniques » catalanes des $\mathrm{XIII}^{\mathrm{e}}$ et $\mathrm{XIV}^{\mathrm{e}}$ siècles ${ }^{3}$, avant de figurer aux côtés du premier roi comme protagoniste de la naissance même du royaume, dans la seconde moitié du $\mathrm{XV}^{\mathrm{e}}$ siècle. $\mathrm{Ce}$ dernier point retient ici toute mon attention, mon propos n'étant pas de saisir le Justicia dans sa configuration historique - ce sujet épineux fait depuis quelques années l'objet de bien des débats entre les historiens ${ }^{4}-$ mais dans le rôle que lui ont prêté les chroniqueurs de l'Orient péninsulaire aux XIV ${ }^{\mathrm{e}}$

Je remercie Martine Charageat et Stéphane Péquignot pour leurs conseils et nos longues discussions sur le sujet, et Jean-Pierre Jardin pour sa lecture attentive et les nombreuses corrections qu'il a bien voulu apporter à ce texte.

${ }^{1}$ Pour une bibliographie sur le Justicia à l'époque moderne, voir les Encuentro(s) sobre el Justicia de Aragón, Saragosse, Justicia de Aragón, publiés depuis 2001. En l'occurrence, sur la récupération du mythe dans l'imaginaire libéral espagnol, ou encore dans la poésie, le théâtre ou la peinture, voir Primer encuentro sobre el Justicia de Aragón, Saragosse, Justicia de Aragón, 2001.

${ }^{2}$ Cette question a été abordée dans un court article par Esteban SARASA SÁNCHEZ, « El Justicia de Aragón en los cronistas ", dans Primer encuentro, op. cit., p. 11-15. Voir aussi Ralph A. GIESEY, If not, not, the oath of the aragonese and the legendary laws of Sobrarbe, Princeton New Jersey, Princeton University Press, 1968 et plus récemment par Jesús MORALES ARRIZABALAGA, « La « foralidad aragonesa » como modelo político : su formación y consolidación hasta las crisis forales del siglo XVI », Cuadernos de estudios borjanos, XXVIIXXVIII, Saragosse, Institución Fernando el Católico, 1992, p. 101-175.

${ }^{3}$ Il s'agit du Livre des faits de Jacques $\mathrm{I}^{\mathrm{er}}$ et de la chronique de Desclot à la fin du XIII ${ }^{\mathrm{e}}$ siècle, de l'œuvre de Muntaner et de la chronique de Pierre IV au XIV siècle.

${ }^{4}$ Concernant l'histoire du Justicia d'Aragon, voir les informations recueillies par María Luz RODRIGO, Documentos para la historia del Justicia de Aragón. Saragosse, Archivo histórico de la Corona de Aragón, 1991, volume 1. Pour une approche plus globale de la charge, voir Luis GONZÁLEZ ANTÓN, El Justicia de 
Sophie HIREL-WOUTS, « Le Justicia dans quelques chroniques de la Couronne d'Aragon » dans Carlos HEUSCH et Georges MARTIN (dir.), Cahiers d'études hispaniques médiévales, 29, Lyon, ENS Éditions, 2006, p. 277-300.

et $\mathrm{XV}^{\mathrm{e}}$ siècles, dont la production - soulignons-le au passage - est encore en grande partie désertée et méconnue 5 .

En 1372, la Chronique de Saint-Jean de la Peña ${ }^{6}$, par ailleurs considérée comme la première chronique nationale aragonaise, ne souffle mot du Justicia; en 1499, le moine de Santa Fe Gaubert Fabrice de Vagad, dans sa Corónica de Aragón', en magnifie les fonctions, chante l'excellence de la charge et le caractère exemplaire de ses origines. Entre ces deux dates - ces deux œuvres - un discours cohérent et puissant s'est construit de toute pièce, récupéré d'une chronique à l'autre, amélioré et étoffé jusqu'à constituer un véritable récit mythique. Comment est né ce mythe et à quelles fins ? Quelle est la nature et l'évolution du discours qui l'a porté ? Quelles sont les modalités de sa naissance, de son enracinement et de sa diffusion dans la production historiographique de l'Espagne orientale?

A la croisée de l'histoire des idéologies, où l'imaginaire investit une réalité institutionnelle, et de la poétique, qui s'exprime à travers un récit paradigmatique, je cherche à montrer que le discours historiographique sur le Justicia d'Aragon est une fiction délibérée et consciemment élaborée, avec l'opportunisme qui les caractérise, par les oligarchies de la Couronne d'Aragon (essentiellement catalanes et valenciennes, d'ailleurs) dans le cadre de stratégies politiques visant à contrecarrer une

Aragón, Saragosse, Caja de Ahorros de la Inmaculada, 2000 ; Idem, «La Corona de Aragón. Regimen político y cortes. Entre el mito y la revisión historiográfica », dans Historiographie de Couronne d'Aragon. Actes du XII Congrès d'Histoire de la Couronne d'Aragon, Montpellier, 1985, p. 61-81 ; Idem, "Alfonso V, las cortes aragonesas y la batalla en torno al justiziazgo ", dans Aragón en la Edad Media : XIV-XV. Homenaje a Carmen Orcástegui Gros, Saragosse, Universidad de Zaragoza, 1999, p. 709-720 ; Idem, « La monarquía de Jaime II y el Justicia de Aragón (Salanova y los procesos contra la rebeldía unionista de 1301) », dans Segundo encuentro de estudios sobre El Justicia de Aragón, Saragosse, El Justicia de Aragón, 2002, p. 93-104. Les historiens sont confrontés sur ce sujet à une mythification qui ralentit et perturbe considérablement les analyses et dont Andrés Giménez Soler dénonçait déjà les effets. Voir Andrés GIMÉNEZ SOLER, «El poder judicial en la corona de Aragón », dans Memorias leída en la Real Academia de Buenas Letras de Barcelone, Barcelone, Tipografia de la Casa provincial de Caridad, 1901, p. 25 :

« Historiar este magistrado es más ardua tarea que las anteriores ; hay tanto y tanto acerca de su origen, atribuciones, eficacia é historia externa y se hallan tan mezclados la verdad y el error, que ya que no otra cosa entorpece la marcha, obliga a paros frecuentes que distraen la atención y rompen la unidad».

Cent ans plus tard, la situation n'a guère changé, et Luis González Antón peut encore écrire [« Alfonso V », op. cit., p. 710] :

« Es una cuestión deficientemente conocida aún, y la razón principal es que todavía hoy la Magistratura sigue inspirando visiones extremadamente apasionadas y simplistas cuando no deliberadamente equívocas ».

${ }^{5}$ En dépit de son intrinsèque diversité - la Couronne d'Aragon réunit sous sa coupe les royaumes d'Aragon (1035), de Valence (1238), de Sardaigne (1297), de Majorque et de Sicile (tous deux rattachés à une branche cadette) ainsi que les comtés de Catalogne (1137) et du Roussillon (1172) - cette historiographie s'est vue majoritairement réduite au domaine strictement catalan, sans doute sous l'effet d'un « parti pris catalaniste de la recherche » par ailleurs dénoncé par Antonio UBIETO ARTETA, Historia de Aragón (creación y desarrollo de la Corona de Aragón), Saragosse, Anubar, 1987, p. 9.

${ }^{6}$ Carmen ORCÁSTEGUI GROS, éd., Crónica de San Juan de la Peña (version aragonaise), Saragosse, Institución Fernando el Católico, 1986.

${ }^{7}$ Fabricio Gauberto de VAGAD, Carmen ORCÁSTEGUI GROS, éd., Corónica de Aragón, Saragosse, Cortes de Aragón, 1996 (édition en fac-similé de l'incunable de 1499). 
Sophie HIREL-WOUTS, « Le Justicia dans quelques chroniques de la Couronne d'Aragon » dans Carlos HEUSCH et Georges MARTIN (dir.), Cahiers d'études hispaniques médiévales, 29, Lyon, ENS Éditions, 2006, p. 277-300.

représentation d'un pouvoir royal fort. Je m'intéresserai particulièrement à la " genèse souterraine ${ }^{8}$ de ce récit au sein de l'historiographie de la Couronne d'Aragon, aux mécanismes de transmission et d'activation ainsi qu'aux étapes de construction de cette mythologie nouvelle qui a marqué durablement l'historiographie de la Couronne d'Aragon.

\section{I. « GENESE SOUTERRAINE » D'UN MYTHE}

La très grande majorité des chroniques de l'Orient péninsulaire adopte, jusque tard dans le Moyen Age, le modèle de l'historiographie navarraise en œuvre dans la chronique du navarro-castillan Jiménez de $\operatorname{Rada}^{9}$ : la dynastie royale qui débute avec Iñigo Arista est strictement navarraise; la descendance de ce roi - son fils Garcia Iñiguez, son petit-fils Sanche Abarca et son arrière petit-fils Garcia - mène directement à Sanche le Grand, dont la partition des territoires donne enfin naissance au royaume d'Aragon (en 1035). Dans les premiers siècles après la conquête, donc, nulle mention d'un royaume d'Aragon. L'Aragon en tant que comté n'apparaît - et encore, subordonné à la Navarre qu'après l'union du comte de Barcelone Sinofre avec la fille du roi de Navarre Sanche Abarca. Le territoire initial, celui de Garcia Jiménez, berceau de la Reconquête dans l'est péninsulaire, est une entité strictement navarraise, et le premier roi, Iñigo Arista, est appelé roi de Pampelune. Comment donc, à contre-courant de la tradition historiographique castillano-navarraise, a pu s'imposer la figure d'un Justicia qui suppose tout à la fois une origine proprement aragonaise du royaume, un roi élu dès le début de la reconquête et un fonctionnement juridico-politique propre dominé par le respect des fors et des libertés aragonaises?

\section{Processus de « sobrarbisation »}

Un premier élément en faveur de la mise en place du récit du Justicia fut la progressive revendication dans l'historiographie de la Couronne d'Aragon d'un accès précoce de l'Aragon au statut de royaume ${ }^{10}$. Dès la fin du $\mathrm{XIV}^{\mathrm{e}}$ siècle, les chroniqueurs de la Couronne ont commencé à mettre en place un territoire primitif aragonais, chaque fois moins associé à la Navarre. Le chroniqueur

\footnotetext{
${ }^{8}$ J'emprunte cette expression à Georges MARTIN, Les juges de Castille, Mentalités et discours historique dans l'Espagne médiévale, Paris, Klincksieck, 1992.

${ }^{9}$ Rodericus XIMENIUS DE RADA, Opera, Saragosse, Anubar (Textos medievales, 22), 1985, index de lieux et de personnes préparés par María Desamparados CABANES PÉCOURT (Ré-impression en fac-similé de l'édition de 1793). Voir livre V, chapitres XXI-XXVI. Pour la traduction contemporaine castillane, voir Rodrigo JMÉNEZ DE RADA, Historia de los hechos de España, introducción, traducción, notas e índices de Juan Fernández VALVERDE, Madrid, Alianza Editorial, 1989.

${ }^{10}$ Sur ce point, voir Jean-Pierre JARDIN et Georges MARTIN, « Generatio regum aragonum. Une variante médiévale inédite de l'histoire des rois d'Aragon (et une source non identifiée de Lucio Marineo Sículo) », Cahiers de linguistique hispanique médiévale, Paris, Klincksieck, 1999, 22, p. 190-191.
} 
Sophie HIREL-WOUTS, « Le Justicia dans quelques chroniques de la Couronne d'Aragon » dans Carlos HEUSCH et Georges MARTIN (dir.), Cahiers d'études hispaniques médiévales, 29, Lyon, ENS Éditions, 2006, p. 277-300.

Jacques Domenech ${ }^{11}$ marque dès 1380 un premier infléchissement dans le processus d'aragonisation de la proto-histoire du royaume. Remaniant la Chronique de Saint-Jean de la Peña, considérée comme fondatrice de la tradition historiographique aragonaise ${ }^{12}$, il conserve certes la souche navarraise des premiers rois en terres pyrénéennes (« et cette année [858] Garcia Jiménez a commencé à régner en Navarre $»)^{13}$, mais élargit l'implantation territoriale du pouvoir de Garcia Jiménez : celui-ci, après avoir conquis Pampelune, devient le premier roi de Navarre mais domine également l'Aragon grâce au vasselage du comte Aznar, ce qui autorise notre chroniqueur à conclure que Garcia Jiménez fut le « premier roi de Navarre et d'Aragon $»^{14}$.

Plus téméraire, le chevalier Tomich accorde aux Aragonais un rôle résolument plus important dans l'émergence de la dynastie naissante. Se réclamant, comme souvent dans ses Histoires et conquêtes des rois d'Aragon et comtes de Barcelone (1438), du tolédan Jiménez de Rada, il souligne que le roi Iñigo Arista a été élu par décision commune des Navarrais et Aragonais. Après la mort de Sanche Garcia, nous dit le chroniqueur, «le royaume et le comté restèrent sans héritier et comme le rapportent les histoires du grand archevêque tolédan, par les Navarrais et Aragonais fut élu un roi, ainsi que vous l'entendrez ci-dessous $»^{15}$, laissant entendre que ces derniers agissent dès le début à part égale avec les Navarrais. L'imposture de Tomich est ici de faire valoir l'autorité du Tolédan pour mieux la pervertir car, de fait, jamais Jiménez de Rada n'a fait intervenir les Aragonais dans cette décision ${ }^{16}$. Cette irruption des Aragonais dans l'élection d'un roi commun est bientôt reprise par le prince de Viana, héritier du royaume de Navarre par sa mère Blanche et de celui d'Aragon par son père Jean. Dans sa Chronique des rois de Navarre qu'il achève en 1454, il montre en effet que les Aragonais, au moment de choisir leur nouveau roi, ne sont plus confinés à un rôle subalterne mais tout autant acteurs de leur histoire que les Navarrais ${ }^{17}$. Cette tendance s'accentue encore dans le dernier tiers du $\mathrm{XV}^{\mathrm{e}}$ siècle et

\footnotetext{
${ }^{11}$ Jaime DOMENECH , Pedro LÓPEZ ELUM, éd., Cronica, Valence, Anubar (Textos medievales, 42), 1975.

${ }^{12}$ Elle est en effet considérée comme fondatrice d'une historiographie proprement aragonaise dans la mesure où le système généalogique qu'elle propose pour les premiers temps la distingue de toute la tradition historiographique navarraise antérieure.

${ }_{13}^{13}$ Jaime DOMENECH, op. cit., p. 54 : « sub quo anno cepit regnare in Navarra Garcia Ximenis ».

${ }^{14} \mathrm{Ibid}$., p. 55 : « primus igitur rex Navarre et Aragonie quantum ad altum dominum fuit Garcia Ximinis ».

${ }^{15}$ Pere TOMICH, Histories e conquestes dels reyes d'Arago e comtes de Catalunya, índices por Juan SAEZ RICO, Valence, Anubar (Textos medievales, 29), 1970 (fac-similé de l'édition de 1534), p. 30 : « romangueren los Regne e Comtat sens hereter e segons recomtan les sues histoires del gran archabisbe Toleda per los Nauarresos e Aragonesos fou elegit un rey axi com dauall hoyreu. Car sapiau que apres la mort del rey Sanxo Garcia dessus dit los Navarresos e Aragonesos romangueren sens rey e senyor e los dessus dits no volent estar sens Rey elegiren per lur rey vn caualler de Bigorra lo qual era appelat per son nom Eniego ».

${ }^{16}$ A moins que Pierre Tomich ne se soit inspiré d'une traduction ou d'une version de l'œuvre du Tolédan encore inédite, la version est la suivante : Rodericus XIMENIUS DE RADA, op. cit., livre V, chapitre XXI, p. 112 : «Cum enim Castella, Legio, et Navarra variis Arabum incursionibus vastarentur, vir advenit ex Bigorciae Comitatu, bellis et incursibus ab infantia assuetus, qui Enecho vocabatur, et quia asper in proeliis, Arista agnomine dicebatur, et in Pyrenaei partibus morabatur, et post ad plana Navarrae descendens, ibi plurima bella gessit : unde et inter incolas regni meruit principatum».

${ }_{17}$ Carlos de VIANA, José YANGUAS Y MIRANDA, éd., Crónica de los reyes de Navarra, Valence, Anubar (Textos medievales, 27), 1971. Voir chapitre 7, p. 40-41: «Como quiera que los dichos navarros, e aragoneses, hobiesen deliberado de levantar rey, como dicho es, pasaron asaz tiempo que no lo ficieron por algunas disensiones que entreillos corrian».
} 
Sophie HIREL-WOUTS, « Le Justicia dans quelques chroniques de la Couronne d'Aragon » dans Carlos HEUSCH et Georges MARTIN (dir.), Cahiers d'études hispaniques médiévales, 29, Lyon, ENS Éditions, 2006, p. 277-300.

s'immisce jusque dans le discours traditionnel. C'est le cas, par exemple, dans le Sumari d'Espanya per Berenguer de Puigpardines ${ }^{18}$ qui, tout en conservant l'origine navarraise du premier roi, ne peut s'empêcher d'associer constamment les rois de Navarre aux comtes d'Aragon, plaçant roi et comte sur un même piédestal : tous les exploits narrés leur sont communs et leurs deux titres (roi de Navarre et comte d'Aragon) sont en permanence réunis sous la plume du chroniqueur. Ainsi lors de la prise de Tolède par les Arabes, l'auteur du Sumari précise que «les rois maures firent la guerre au roi de Navarre et au comte d'Aragon, qui étaient fort bons chevaliers » et unit les deux hommes jusque dans la mort, comme s'ils ne formaient qu'une seule et même personne : «Et morts les rois Garcia Iñigo, et le roi Fortun Garcia, et le bon comte Aznar, les Aragonais restèrent sans seigneur ${ }^{19}$. Rédigé vers 1466, bien qu'il prétende l'avoir été du temps de Raymond Bérenger de Barcelone (XII ${ }^{\mathrm{e}}$ siècle), ce texte reprend bien le modèle antérieur selon lequel Garcia Iñigo et ses descendants sont exclusivement rois de Navarre, mais submerge ce discours sous le flot des hauts faits des comtes aragonais.

L'initiative de Tomich a donc fait date et a volontiers été reprise («à la lettre» ou librement transposée) dans la tradition historiographique de la seconde moitié du $\mathrm{XV}^{\mathrm{e}}$ siècle. Mais il y a plus : non content de donner aux Aragonais un rôle accru dans le choix du premier roi, notre chroniqueur leur fournit un territoire propre, sitôt érigé en royaume. Sur les conseils de deux saints hommes réfugiés dans les montagnes du Sobrarbe, les chrétiens ont élu un roi (Garcia Jiménez) « et ce roi fut bon et vertueux chevalier, et avec ce petit nombre de chrétiens il soumet toutes les montagnes susdites de Sobrarbe et de Ribagorza, et de ces montagnes il s'intitule roi $»^{20}$. Le chroniqueur de Bagà impose ainsi un titre royal originel, celui de roi des montagnes de Sobrarbe et de Ribagorza, et précise que les descendants de ce premier roi, son fils Garcia Iñigo et son petit-fils Fortun, sont rois de « Navarre et de Sobrarbe et de Ribagorza ", déplaçant ainsi de la Navarre au Sobrarbe et au Ribagorza le noyau primordial de Garcia Jiménez. Aucun de ces «symptômes du Sobrarbe », pour reprendre l'expression de Ralph Giesey ${ }^{21}$, n'est présent dans la chronique de Rada, pas plus que dans la Chronique de SaintJean de la Peña. Ces indices apparaissent pour la première fois (du moins, d'après les textes qui nous sont parvenus) sous la plume du catalan Tomich dans la première moitié du $\mathrm{XV}^{\mathrm{e}}$ siècle avant d'être repris et radicalisés dans la seconde moitié de ce même siècle par certains chroniqueurs aragonais soucieux de magnifier les origines de leur royaume. Entre 1464 et 1479, l'auteur du Generatio,

\footnotetext{
${ }^{18}$ Voir Joan IBORRA, éd., Sumari d'Espanya per Berenguer de Puigpardines, Valence, Universitat de Valencia, 2000. On désigne sous ce titre deux manuscrits répondant cependant à des objectifs bien différents. Le premier, le manuscrit A, reprend le modèle de la Chronique de Saint-Jean de la Peña et plaide largement en faveur des intérêts du comté de Barcelone ou de ceux de la Couronne; l'autre, le manuscrit B, reprend et amplifie les innovations de Tomich dans le sens d'une défense opiniâtre des intérêts de la noblesse catalane. Seul le manuscrit B consigne l'existence d'un Justicia, et, pour cette raison, intéresse mon discours. L'éditeur avance 1468 comme date possible d'achèvement de cette chronique.

${ }^{19} \mathrm{Ibid}$, p. 175 : «E morts los reys Garcia Ényego, e lo rey Fortun Garcia, e lo bon compte Aznar, los aragonesos romangueren sens senyor algú ».

${ }^{20}$ Pere TOMICH, op . cit., p. 29 : « e aquell rey [Gracia Ximenez] fou bon caualler e virtuos que ab aquells pochs chrestians se subiuga totes les muntanyes dessus dites de Subarbia e de Ribagorca, et daquelles muntanyes se intitula Rey ".
} 
Sophie HIREL-WOUTS, « Le Justicia dans quelques chroniques de la Couronne d'Aragon » dans Carlos HEUSCH et Georges MARTIN (dir.), Cahiers d'études hispaniques médiévales, 29, Lyon, ENS Éditions, 2006, p. 277-300.

probablement Jean $\mathrm{II}^{22}$, met en effet en scène un Garcia Jiménez élu roi « dans la province d'Aragon » par les chrétiens réfugiés à Saint-Jean de la Peña. L'enracinement traditionnel des rois d'Aragon dans la royauté navarraise demeure, comme le soulignent Jean-Pierre Jardin et Georges Martin, mais l'auteur prend soin de spécifier que seul le second roi de la dynastie, le fils de Garcia Jiménez, prend le titre de roi de Navarre. Gaubert Fabrice de Vagad, pour sa part, dans la Chronique d'Aragon qu'il semble avoir composée au long des années 1465-1499, force le trait et dément formellement ceux qui qualifient Garcia Jiménez de roi de Navarre : «Certains chroniqueurs trop peu prudents ont osé écrire que le magnanime roi don Garcia Jiménez devait à plus juste titre être appelé roi de Navarre que roi de Sobrarbe, et c'est ainsi qu'ils l'ont appelé dans quelques-unes de leurs chroniques (corónicas), mais sans nous en donner la raison, sans préciser ni où ni quand, ni comment ni par qui ce roi aurait été élu en Navarre $»^{23}$. Dans la version vagadienne, seul le fils de Garcia Jiménez, encore une fois, ajoute le titre de roi de Navarre aux titulatures héritées de son père. Ce dernier et tous ses descendants sont dans ce texte rois de Sobrarbe, immanquablement, et si Ramire est bien le premier roi d'Aragon, il est avant tout le dixième « roi de Sobrarbe». Cette mention apparaît en tête des titulatures tout au long de la généalogie que Vagad décline et rattache ainsi directement l'histoire de l'Aragon dans son ensemble à l'élection de Garcia Jiménez. De l'avis de Ralph Giesey, «c'est peut-être là l'intérêt majeur de la chronique de Vagad: par cette simple duperie généalogique, il jette les bases d'une formidable diffusion de la légende du Sobrarbe $»^{24}$. Cette «duperie généalogique», qui n'est autre que l'exacerbation des innovations tomichiennes, constitue un point de non retour dans l'historiographie aragonaise et une base solide pour l'épanouissement de la légende du Justicia. Même Lucio Marineo Sículo, qui par ailleurs ne manque pas de fustiger la chronique de Vagad, d'en critiquer le style et les artifices, ne peut faire marche arrière ${ }^{25}$. Évitant toute mention d'une dynastie royale navarraise antérieure à l'existence des rois d'Aragon, ce chroniqueur renchérit explicitement sur Vagad en présentant Garcia Jiménez comme roi du Sobrarbe et en privant du titre de roi de Navarre non seulement le premier fondateur mais encore tous ses descendants et même l'ensemble des représentants de la seconde dynastie royale, Sanche le Grand inclus.

\footnotetext{
${ }^{21}$ Ralph A. GIESEY, op. cit., p. 105.

${ }^{22}$ Pour une étude sur la datation du texte et sur l'identité de son auteur, voir Jean-Pierre JARDIN et Georges MARTIN, op. cit., p. 221.

${ }^{23}$ Fabrice Gaubert de VAGAD, op. cit., fol. VIII : «Osaron escreuir algunos coronistas no assaz auisados que el rey magnánimo don Garci Ximenez más de razón se deuía llamar rey de Nauarra que no de Sobrarbre, y assí le llamaron en algunas de sus corónicas, mas sin nos dar d'ello razón, sin assignar dónde ni quándo, cómo ni por quién fuera tal rey en Nauarra escogido, y en callarnos la razón publicaron más su mengua y refuyeron la verdad».

${ }^{24}$ Ralph A. GIESEY, op. cit., p. 107 : «This, then, is perhaps, the greatest importance of Vagad's Corónica : by his simple genealogical trickery he set the stage for a tremendous expansion of the legend of Sobrarbe ».

${ }^{25}$ Le bachelier Molina, qui rédigea le prologue de la première impression de l'oeuvre de Marineo Sículo, partage avec ce dernier une hostilité manifeste contre Vagad. Voir Lucio MARINEO SÍCULO, Crónica Daragón, Barcelone, Albir, 1974, prólogo, fol. III : «procede [el autor] en el con harto mejor y menos passion que el reverendo padre fray Gauberte procedio en el suyo que desta misma materia escrivio : el qual me perdone que
} 


\section{Le(s) premier(s) roi(s) d'Aragon}

La deuxième singularité de l'historiographie de la Couronne d'Aragon, induite du processus de sobrarbisation ci-dessus exposé (il n'y a pas de royaume sans roi !), fut de faire remonter au plus loin les origines de la royauté aragonaise. Longtemps, les productions historiographiques tant castillanes, navarraises qu'aragonaises se sont accordées à faire de Ramire, fils (bâtard) de Sanche le Grand de Navarre, le premier roi d'Aragon. Les chroniques de la Couronne d'Aragon dans la seconde moitié du $\mathrm{XV}^{\mathrm{e}}$ siècle offrent une nouvelle version des faits...

C'est semble-t-il par erreur que la chronique dite de 1427, vraisemblablement rédigée sous le règne d'Alphonse V, attribue à Sanche Abarca le titre de premier roi d'Aragon ${ }^{26}$. Dans le méli-mélo généalogique que constitue dans cette chronique le récit de la naissance du royaume d'Aragon, Sanche Abarca et Ramire sont confondus, et les désormais traditionnels exploits de l'un constamment attribués à l'autre. "Traditionnels », en effet, car depuis la Cronica Najerensis, le courage et les vertus de Ramire font l'objet d'un récit paradigmatique dont la trame est la suivante: ce fils bâtard de l'empereur Sanche le Grand sauve sa belle-mère d'une accusation d'adultère portée contre elle par ses propres fils, notamment par son aîné Garcia, à qui elle vient de refuser le cheval blanc de l'empereur. Ramire se propose de lutter contre les accusateurs, qui préfèrent alors confesser leur mensonge. En récompense de son courage et de son dévouement, il reçoit de la reine le royaume d'Aragon alors qu'à Garcia, Ferdinand et Gonzague reviennent respectivement la Navarre, la Castille et le Ribagorza. La légende permet d'expliquer la répartition des territoires de Sanche le Grand et l'accession au trône d'Aragon de Ramire $\mathrm{I}^{\text {er }}{ }^{27}$. Le rôle de Ramire est ici incarné par Sanche Abarca qui « fut ainsi fait roi d'Aragon $»^{28}$, mais qu'importe la confusion quand il s'agit d'assurer la légitimité d'un royaume, d'asseoir ses droits sur certains territoires, d'affirmer sa prééminence et son antériorité sur tout autre royaume, bref, de souligner le caractère merveilleux et par conséquent inaliénable de ses fondations ?

Le manuscrit B du Sumari d'Espanya per Berenguer de Puigpardines opère quant à lui avec bien plus de discernement en accordant à Sanche Abarca le titre de premier roi d'Aragon. Dans un coup de

\footnotetext{
justamente y con gran razon no es leydo e para siempre sepultado en el rincon del universal odio cubierto con la piedra del olvido $\gg$.

${ }^{26}$ Bibliothèque Nationale de Madrid, manuscrit 17 711, fol. 152

${ }^{27}$ Pour une analyse de l'évolution du motif légendaire dans l'historiographie aragonaise, voir José Luis MARTIN, « No hay historia sino historiadores », dans Aragón en la Edad Media. Homenaje a la profesora Carmen Orcástegui Gros, op. cit, p. 991-1004. Sur la « répartition » des royaumes à la mort de Sanche le Grand, voir Antonio UBIETO ARTETA, Historia de Aragón. Orígenes de Aragón, Saragosse, Anubar, 1989, p. 313330 .

${ }^{28}$ Op. cit., fol. 152 : « la dita reyna prega al rey que li plagues que ella pogues donar Muntarago e totes les muntanyes al dit don Sancho auarcha e que fos rey darago e axi fou fet rey darago ».
} 
Sophie HIREL-WOUTS, « Le Justicia dans quelques chroniques de la Couronne d'Aragon » dans Carlos HEUSCH et Georges MARTIN (dir.), Cahiers d'études hispaniques médiévales, 29, Lyon, ENS Éditions, 2006, p. 277-300.

force inédit, l'auteur fait de ce dernier non plus le fils du roi Garcia Iñigo (de Navarre), mais celui du comte et de la comtesse d'Aragon. Il reprend le récit de la naissance fabuleuse de l'enfant, mais le détaille plus que ne le fait de coutume la tradition historiographique : il signale l'arrivée d'un noble chevalier à l'endroit où gît le corps de la " comtesse », s'attarde sur l'accouchement " posthume » dont le noble est témoin, évoque longuement l'éducation reçue par l'enfant miraculé avant de conclure sur son avènement royal, après que les Aragonais se sont retrouvés libérés de la tutelle navarraise ${ }^{29}$. Le choix de ces derniers s'est «naturellement» tourné vers l'enfant recueilli par le noble, qui leur a révélé et certifié la naissance miraculeuse du fils du comte. Et tous les Aragonais réunis de s'écrier : "Vive, vive notre nouveau roi et seigneur naturel que par la grâce de Dieu voici » ${ }^{30}$. Le terme « nouveau » («novell », qui n'apparaît pas dans la chronique du prince de Viana) signale davantage l'avènement d'une première dynastie que la jeunesse de Sanche Abarca. Il ressort cependant de ce texte une très forte continuité entre l'histoire de l'Aragon comme comté et l'histoire du royaume, puisque le premier roi du royaume est aussi le seigneur naturel de la terre : non pas un étranger, mais le descendant direct des comtes d'Aragon. L'identité navarraise de la première dynastie royale (celle d'Iñigo Arista) se trouve ainsi niée au profit de l'Aragon, dont les origines sont renvoyées aux premiers temps de la reconquête.

Dans le dernier tiers du $\mathrm{XV}^{\mathrm{e}}$ siècle, enfin, les positions se radicalisent. Le texte du Generatio, la chronique de Vagad ou encore celle de Sículo n'hésitent pas à remonter encore plus loin dans le temps. Si les chroniques des deux premiers tiers du $\mathrm{XV}^{\mathrm{e}}$ siècle identifiaient le premier roi non plus à Ramire $\mathrm{I}^{\mathrm{er}}$ (1035) mais à Sanche Abarca (soit à la fin du $\mathrm{X}^{\mathrm{e}}$ siècle) ou à Iñigo Arista (au début du $\mathrm{IX}^{\mathrm{e}}$ siècle), ceux de la seconde moitié du siècle remontent à la dynastie antérieure et présentent Garcia Jiménez (au VIII ${ }^{\mathrm{e}}$ siècle) comme premier roi des Aragonais : il est «regis aragonum» dit le Generatio, « roi des nôtres » répète le très aragonais Vagad. Certes, celui-ci précise que Garcia Jiménez est roi des Aragonais et non de l'Aragon, mais reliant ce dernier au noyau originel du Sobrarbe, il fait indéniablement de Garcia Jiménez le père de l'Aragon. Il consacre d'ailleurs dix longs folios à ce premier roi de Sobrarbe, là où les autres chroniques n'excèdent guère quelques lignes, exaltant le bien-fondé, la pertinence et l'excellence de ce moment inaugural.

Ce n'est cependant pas, loin s'en faut, le seul modèle adopté par les chroniqueurs de la Couronne d'Aragon ; face à cette sobrarbisation des fondements du royaume d'Aragon persiste la version traditionnelle soutenant le caractère navarrais de la première dynastie royale. La concurrence entre les deux versions et la prééminence progressive (et agressive) de la version pro-aragonaise sur la pro-

\footnotetext{
${ }^{29}$ Voir Joan IBORRA, éd., op .cit., p. $177:$ : E lavors, fon dit e posat que pus que Aragó era absolt del rey de Navarra de tot vassalatge e subjugació de aquell, feya a veure qui porian haver per rey e senyor e, puys ajustats eren, que n'elegissen hu ».

${ }^{30} \mathrm{Ibid}$., p. 177 : «Viva! Viva ! Lo nostre novell rey e senyor natural que per gràcia de Déu havem ací ! ».
} 
Sophie HIREL-WOUTS, « Le Justicia dans quelques chroniques de la Couronne d'Aragon » dans Carlos HEUSCH et Georges MARTIN (dir.), Cahiers d'études hispaniques médiévales, 29, Lyon, ENS Éditions, 2006, p. 277-300.

navarraise témoignent de l'émergence d'une conscience nationale au sein du royaume d'Aragon ${ }^{31}$ et de la volonté de faire du noyau originel de l'Aragon - appelé Sobrarbe - un territoire non seulement indépendant de la monarchie navarraise, mais surtout régi par des lois propres antérieures à toute royauté. Cette manipulation d'indices géographiques (géopolitiques) et généalogiques qui inscrit les origines de la monarchie aragonaise dans un paysage nouveau s'accompagne en effet - dans la seconde moitié du $\mathrm{XV}^{\mathrm{e}}$ siècle - d'un renouveau des thèses pactistes.

\section{Des fors au « pactisme » : des lois avant le roi...}

A la base historique formée par le couple royaume-roi de Sobrarbe allait sans grande difficulté être rattachée une base juridique témoignant du caractère pactiste du fonctionnement politique aragonais, dont l'origine est renvoyée aux fors de Sobrarbe. Dans cette association d'arguments historique et juridique à des fins somme toute politiques résident, à mon sens, la force et la cohérence du récit qui nous intéresse présentement.

Si les fors de Sobrarbe n'évoquent, dans un premier temps, que les privilèges octroyés par Pierre $\mathrm{I}^{\mathrm{er}}$ aux infanzones de Barbastro au début du XII ${ }^{\mathrm{e}}$ siècle, ils sont bientôt associés au for général de Navarre qui rappelle - dans le dernier quart du $\mathrm{XIII}^{\mathrm{e}}$ siècle - qu'une poignée d'hommes réfugiés dans les montagnes des Pyrénées a reconquis une partie du territoire sur les Maures avant d'élire un roi. Cette décision, nous informe le texte, fut consécutive aux dissensions nées entre ces chrétiens quant à la répartition des butins pris sur les Maures et elle leur fut conseillée par le pape, les Lombards et les Français auxquels ils avaient eu recours. Cette élection, toutefois, ne devait pas se faire avant que les Navarrais aient inscrit leurs fors par écrit : «[...] et ils firent ainsi qu'on leur avait conseillé, et ils écrivirent leurs fors sur le conseil des Lombards et des Français, du mieux qu'ils purent comme des hommes qui gagnaient les terres des Maures $»^{32}$. A un moment où la noblesse navarraise lutte pour ses privilèges face à des dynasties étrangères chaque fois plus pressantes, cette dernière mesure apparaît comme le rempart ultime, la garantie de l'intégrité du royaume. Le message politique est clair : les fors sont antérieurs à la royauté qui doit, par conséquent, s'y soumettre. Le Sobrarbe étant le point le plus à l'est de la retraite de ces chrétiens, le for général de Navarre fut aussi appelé for de Sobrarbe...

\footnotetext{
${ }^{31}$ Voir les travaux de José Ángel SESMA MUÑOZ, et notamment : « Estado y nacionalismo en la baja Edad Media. La formación del sentimiento nacionalista aragonés », dans Aragón en la Edad Media, VII, Saragosse, Universidad de Zaragoza, 1987, p. 245-273 ; et du même auteur «El sentimiento nacionalista en la Corona de Aragón y el nacimiento de la España moderna ", dans Realidad e imágenes del poder. España a fines de la Edad Media, Valladolid, 1988, p. 215-231.

${ }^{32}$ Pablo ILARREGUI et Segundo LAPUERTA, éd., Fuero general de Navarra, Pamplona, Imprenta Provincial, 1869, p. 1-2 : « [El apostóligo Aldebano et ombres de Lombardia et de Francia] enbiáronles dizir que oviessen rey por qui se caudeyllassen; et primeramente que oviessen lures establecimientos jurados et escriptos; et ficieron como los conseyllaron, et escrivieron lures fueros con conseio de los lonbardes et franceses, quoanto eyllos meior podieron como ombres que se ganavan las tieras de los moros".
} 
Sophie HIREL-WOUTS, « Le Justicia dans quelques chroniques de la Couronne d'Aragon » dans Carlos HEUSCH et Georges MARTIN (dir.), Cahiers d'études hispaniques médiévales, 29, Lyon, ENS Éditions, 2006, p. 277-300.

Présent dès la fin du $\mathrm{XIII}^{\mathrm{e}}$ siècle dans la littérature juridique, ce thème n'a toutefois pas suscité grand intérêt dans l'historiographie du $\mathrm{XIV}^{\mathrm{e}}$ siècle, et il faut attendre la première moitié du $\mathrm{XV}^{\mathrm{e}}$ en Navarre et la seconde en Aragon pour le voir reverdir dans les chroniques. Les raisons déterminantes de ce «renouveau » des thèses pactistes dans l'historiographie de l'Orient péninsulaire sont sans aucun doute à replacer dans la dynamique des rapports de pouvoir entre le roi et les autres forces en présence (les noblesses et les élites urbaines) et dans le cadre plus large des transformations politiques qui touchent la Couronne d'Aragon dans le dernier siècle du Moyen Age : l'influence de l'avènement d'un Trastamare sur le trône aragonais suite au compromis de Caspe en 1412 et celle de l'union dynastique des royaumes d'Aragon et de Castille suite au mariage de Ferdinand et d'Isabelle en 1469 ont souvent été alléguées pour expliquer l'ensemble des perturbations alors ressenties par le royaume $\mathrm{e}^{33}$. Elles sont maintenant débattues tant par des juristes spécialistes de la foralité aragonaise que par des historiens. Dans la sphère qui nous concerne, celle de la production historiographique, notons - mais ce n'est pour l'heure qu'une constatation - qu'aucune chronique postérieure au Compromis de Caspe ne relève de rupture dans la continuité généalogique des rois d'Aragon; l'événement n'a pas semblé marquer les sphères intellectuelles de la Couronne. Dans la seconde moitié du siècle toutefois, le sentiment anti-castillan est patent. Faut-il y voir la manifestation d'une peur d'un absolutisme à la mode castillane ou celle d'un sentiment de nostalgie, dans la mesure où ce renouveau se fait au moment même où le couronnement vient dans une large mesure remplacer le serment royal ${ }^{34}$ ?

Le trésorier de Charles III de Navarre, Garci López de Roncesvalles, reprend la disposition du for général dans le prologue du livre des comptes dont il entreprend la rédaction en 1405 : «Et premièrement il a été établi par for en Espagne de proclamer un roi pour toujours afin qu'aucun roi, jamais, ne puisse leur faire du mal car le conseil, c'est-à-dire le peuple, le proclamait roi et lui donnait ce qu'il avait et ce qu'il gagnait sur les Maures $»^{35}$. Dès l'incipit, l'auteur ne cesse de vanter la primauté du for sur le roi, faisant de celle-ci la quintessence même des origines du royaume (dans le cas présent, la Navarre) et la force d'un peuple que le roi se doit de protéger. L'idée développée est celle d'un équilibre entre ce que le royaume apporte au roi (les terres) et la protection que peut

\footnotetext{
${ }^{33}$ Cette idée fut notamment défendue par Esteban SARASA SÁNCHEZ et Ángel CANELLAS LÓPEZ, qui voient dans l'avènement du Trastamare l'implantation de l'autoritarisme castillan et la fin de l'esprit pactiste de l'Aragon. A l'opposé, Joan REGLÀ voit dans cet événement la possibilité pour le programme pactiste de se développer dans son ensemble. Vicens VIVÉS, quant à lui, ne croit pas au caractère autoritariste castillan.

${ }^{34}$ Bonifacio PALACIOS MARTIN, La coronación de los reyes de Aragón 1204-1410. Aportación al estudio de las estructuras medievales, Valence, Anubar, 1975, p. 131-184.

${ }_{35}$ Carmen ORCÁSTEGUI GROS, éd., Crónica de Garci López de Roncesvalles. Estudio y edición crítica, Pampelune, Universidad de Navarra, 1977, p. 60-61 : « Nota que aqui ante de los reyes es puesta la cláusula del fuero. Et primeramente fue establido por fuero en Spanna de rey alçar para siempre porque ningun rey jamás qui sería non les podies ser malo pues concello co es pueblo le alcaban rey e li daban lo que ellos habían et ganaban de los moros ; primero que lis iurás ante que lo alcasen, sobre la Cruz et los Evangelios, que los tovies a dreyto et lis meyloras lures fueros, et non lis apeoras et que lis desfizies las fuercas ».
} 
Sophie HIREL-WOUTS, « Le Justicia dans quelques chroniques de la Couronne d'Aragon » dans Carlos HEUSCH et Georges MARTIN (dir.), Cahiers d'études hispaniques médiévales, 29, Lyon, ENS Éditions, 2006, p. 277-300.

apporter le roi (stabilité « para siempre » et sécurité « non ser malo »). Les acteurs de cet équilibre sont clairement définis : le roi d'un côté, le conseil de l'autre, sitôt étendu à la catégorie de "peuple ». Dans la pratique, cet équilibre se solde par un serment du roi, "que lis jurás », dont on sait qu'il se pratique - en Aragon - tout au long du XIV siècle. Placer en tête d'une chronique qui, de l'avis de Carmen Orcástegui Gros, est la première histoire particulière du royaume, soit le texte fondateur de l'histoire navarraise à proprement parler ${ }^{36}$, cette déclaration de principes ne laisse aucun doute sur la teneur des revendications politiques du royaume de Navarre au début du $\mathrm{XV}^{\mathrm{e}}$ siècle.

Un demi-siècle plus tard, un autre navarrais, le Prince de Viana (qui s'inspire par ailleurs abondamment de la chronique de Roncesvalles), renoue avec ce thème dans sa Chronique des rois de Navarre, mais en élargit la sphère d'influence en impliquant, comme nous l'avons mentionné plus haut, les Aragonais dans l'affaire: "Nous, riches hommes, chevaliers et infanzones, et hommes des bonnes villes de Navarre et d'Aragon [...], nous établissons premièrement par for de proclamer un roi pour toujours. [...] Premièrement, qu'il nous prête serment, avant qu'on le proclame, sur la croix et les saints évangiles, de respecter notre droit et d'améliorer toujours nos fors, et de ne pas les empirer ${ }^{37}$. La motivation qui préside à l'établissement de ces fors est encore une fois le nécessaire respect du peuple par le roi, c'est-à-dire le maintien et la défense des libertés et privilèges inaliénables du royaume. Les mesures prises visent en effet à limiter toute action contraire au «bien commun » du "peuple », en réalité les intérêts des classes privilégiées, nouvellement définies par Charles de Viana : l'adjonction de la liste des acteurs, "riches hommes, chevaliers et infanzones, et hommes des bonnes villes de Navarre et d'Aragon », rompt en effet avec les termes génériques (" eux », " le peuple ») employés par le passé et ne laisse aucun doute sur la nature et l'étendue du bien commun à défendre, non pas celui du peuple tout entier, mais celui de ses représentants, les élites du royaume.

Du côté aragonais, l'idée n'est récupérée et développée par les chroniqueurs que dans la seconde moitié du $\mathrm{XV}^{\mathrm{e}}$ siècle. La chronique anonyme de 1427, tout d'abord, se contente de souligner de façon quelque peu laconique que le roi a été élu «selon certains pactes et privilèges ${ }^{38}$. La généalogie vagadienne des rois d'Aragon, pour sa part, est beaucoup plus éloquente. Elle débute d'ailleurs, de façon symptomatique, par un long panégyrique sur l'excellence du pacte initial. Le conseil donné par les saints hommes (en l'occurrence, Oto et Felicio, "naturales de Çaragoça ») est repris et mis en

${ }^{36}$ Carmen ORCÁSTEGUI GROS, éd., Crónica de Garci López de Roncesvalles, Pampelune, Ediciones Universidad de Navarra, 1977, p. 51 : «Es la primera historia específica del reino de Navarra y aislada de las compilaciones generales de España ».

${ }^{37}$ Prince de VIANA, op. cit., chapitre 6, p. 38-39: «Este es el primer capitulo que, con los navarros e aragoneses, establecieron en su fuero general. Nos ricoshombres, cabailleros e infanzones, e hombres de buenas villas de Navarra e Aragon, como aqueillos que siempre tovimos hermandat e buena compañia establecemos primerament, por fuero de levantar rey para siempre ; e por que ningun rey non nos pueda ser malo, pues que consejo, es a saber pueblo, lo levanta e le damos de lo que tenemos, e ganáremos de los moros. Primerament, que nos jure, ante de lo alzar, sobre cruz e sanctos evangelios, que nos tendrá a derecho e amejorará siempre nuestros fueros, e no los apeorará ». 
Sophie HIREL-WOUTS, « Le Justicia dans quelques chroniques de la Couronne d'Aragon » dans Carlos HEUSCH et Georges MARTIN (dir.), Cahiers d'études hispaniques médiévales, 29, Lyon, ENS Éditions, 2006, p. 277-300.

valeur par notre chroniqueur, qui insiste sur la nécessaire unanimité de l'accord originel et sur la réciprocité inhérente au système. Les deux saints hommes recommandent en effet " qu'ils devaient tous d'abord convenir entre eux de comment et de qui ils allaient choisir, et après s'être tous mis d'accord sur la personne, ils devaient tous ensemble lui dire que puisqu'eux, affranchis et libres comme ils l'étaient, voulaient de si bon gré le choisir et le proclamer seigneur, et renoncer pour le suivre à leur propre liberté et volonté, lui aussi devait reconnaitre le grand honneur qu'on lui faisait et partager avec eux le gouvernement du royaume $»^{39}$. Dans ces lignes, si Fabrice Gaubert de Vagad reprend indéniablement le schéma narratif forgé par ses prédécesseurs, il en change toutefois fondamentalement les implications. Il ne s'agit plus seulement ici d'affirmer le caractère foral de la juridiction aragonaise, de déclarer l'antériorité des lois sur le roi, mais de définir un système de gouvernement basé sur une répartition des pouvoirs. La structure du discours autant que le lexique employé marquent la nécessaire réciprocité, le lien de cause à effet de la décision. Les termes sont clairs : les nobles demandent au roi de "partager avec eux le gouvernement du royaume ». Nous sommes en pleine définition du pactisme politique comme mode de gouvernement, comme distribution du pouvoir entre la royauté aragonaise (qui ne peut donc être monarchique) et les élites, le tout basé sur une répartition des fonctions, aires d'influence et bénéfices de chacun des partis. Ce partage est légitimé par la capacité d'un royaume qui a su se gouverner seul dès le début de la reconquête, puis lors des divers interrègnes du royaume. Relativement aux chroniqueurs précédents, Vagad n'hésite pas à signaler la longue durée des interrègnes qui président à la réaffirmation des thèses pactistes. Faut-il voir dans ces évocations une allusion à l'interrègne de 1410-1412 consécutif à la mort de Martin l'Humain, à l'issue duquel Ferdinand le Trastamare arrive sur le trône, ou encore une critique sous-jacente de l'absence prolongée d'Alphonse V ? A l'évidence, l'accent est mis sur la fragilité des rois dans ces moments critiques (autrement dit, sur la force du royaume) ${ }^{40}$. Toutefois, à aucun moment dans la chronique de Vagad, ces fors n'apparaissent comme contraires aux intérêts du roi : ils servent celui-ci au même titre qu'ils protègent les Aragonais. N'est-ce d'ailleurs pas le premier roi lui-même qui, désireux d'échapper à toute tentation absolutiste, a exhorté son peuple à choisir les lois selon lesquelles il voulait être régi? Dans un discours au style direct - qui accentue l'effet dramatique du contenu - Garcia Ximénez affirme en effet : «De la même façon que vous m’avez

\footnotetext{
${ }^{38}$ Crónica anónima de 1427, fol. 152v : « ab certes pactes e privilegis ».

${ }^{39}$ Gaubert Fabrice de VAGAD, op. cit., fol. II : « que deuían todos concertar primero entre si de cómo y a quién hauían de escoger, y después de ser todos concordes cerca de la persona, que deuían todos juntos dezirle, que pues ellos siendo tan esentos y libres querían tan de su grado escogerle y levantarle por señor y renunciar por le seguir su misma libertad y querer, que tanbien el deuía reconoscer la honrra tan grande que en ello se le fazía y repartir con ellos el regimiento del reino ».

${ }^{40}$ Luis LEGAL DE LACAMBRA, El pactismo en la historia de España, Madrid, Instituto de España, Cátedra, 1980 , p. 139 : «El interregno es un caso forzado de absentismo real y las aventuras dinásticas alejan fisicamente los Reyes de sus pueblos, con los que en estos crece el despego a aquéllos y el aumento de sus pretensiones. La constitución de la Corona de Aragón ha contribuido al absentismo, y todavía más su expansión mediterránea. Este absentismo se ha potenciado todavía mucho más cuando la Corona de Aragón se ha unido a Castilla y los Reyes han elegido a ésta como su asiento ».
} 
Sophie HIREL-WOUTS, « Le Justicia dans quelques chroniques de la Couronne d'Aragon » dans Carlos HEUSCH et Georges MARTIN (dir.), Cahiers d'études hispaniques médiévales, 29, Lyon, ENS Éditions, 2006, p. 277-300.

choisi pour roi librement et plus par amour et de bon gré que par obligation, nécessité ou crainte, je veux et je me réjouis de gouverner plus selon votre volonté et votre gré que selon le mien. Choisissez entre vous les lois qui vous agréent le plus et qui sont le plus conformes au bien public et à votre bon gré et vouloir, c'est selon elles que je veux régner et gouverner, mieux : que je veux que nous gouvernions tous $»^{41}$.

L'idée de pacte entre la royauté et la noblesse, qui n'avait pu être formulée très clairement durant les luttes de l'Union, trouve ainsi une nouvelle forme d'expression parmi les juristes et historiens du $\mathrm{XV}^{\mathrm{e}}$ siècle $^{42}$. Ces derniers s'appuient manifestement sur le prologue du For général de Navarre, appelé for de Sobrarbe, et sur la glose qu'en fit le prince de Viana dans sa chronique, mais les transcendent bientôt. En effet, s'il a suffit en Navarre de renforcer le caractère fondateur des fors et de limiter les possibilités de réforme en les consignant dans un For général (à la fin du XIII ${ }^{\mathrm{e}}$ siècle), le royaume d'Aragon, pour sa part, n'a pas voulu se contenter de compiler ses fors et de les rappeler en tête des histoires du royaume ${ }^{43}$. Dans un royaume qui déjà s'était opposé à Jacques $\mathrm{I}^{\mathrm{er}}$ lorsque ce dernier avait tenté d'affirmer le pouvoir législatif du roi en tête de la compilation des fors (dans un texte - In exelsis - sitôt réprouvé par les classes privilégiées), il s'est avéré nécessaire de créer, dès le XIII ${ }^{\mathrm{e}}$ siècle, puis de protéger et sublimer, tout au long des $\mathrm{XIV}^{\mathrm{e}}$ et $\mathrm{XV}^{\mathrm{e}}$ siècles, une figure chargée de consolider les acquis des époques antérieures en matière de libertés et privilèges : le Justicia d'Aragon.

\section{LE JUSTICIA DANS L'HISTORIOGRAPHIE}

Ce n'est pas dans le domaine historiographique à proprement parler qu'est consigné pour la première fois le motif du Justicia, mais dans la Carta Intimada - datée du 25 février 1435 - que l'exJusticia Jiménez Cerdán adresse à Diaz de Aux, son successeur. Dans cette lettre, la figure d'un Justicia originel se glisse subrepticement dans le schéma établi par le for de Navarre. On retrouve en effet sous la plume de Cerdán la mention désormais traditionnelle des premiers chrétiens réfugiés dans les montagnes, le rappel de leurs dissensions et leur décision d'élire un roi ; mais là où le récit vieux de plus d'un siècle et demi concluait sur la mise par écrit des fors, notre auteur annonce l'élection d'un Justicia : « [ils décidèrent] d'élire un roi, mais qu'il y eût un juge entre lui et eux qui s'appelât Justicia d'Aragon ». Enhardi par ce premier tour de force, Cerdán enchaîne sur la possible antériorité du

\footnotetext{
${ }^{41}$ Gaubert Fabrice de VAGAD, op. cit., fol. VII : «Assí como libremente y más por amor y grado que por debda, necessidad ni temor en rey me escogistes, assí me plaze y quiero más a voluntad y grado vuestro regir que no al mío. Escoged entre vosotros las leyes que más vos pluguieren y que más al bien público y a vuestro grado y querer fueren conformes, que segund aquéllas quiero reynar y regir, más : quiero que rijamos todos ».

${ }^{42}$ Le mouvement de l'Union est un mouvement d'opposition au roi qui a débuté sous Alphonse III et a pris fin avec Pierre IV le Cérémonieux. Voir Luis GONZÁLEZ ANTÓN, Las uniones aragonesas y las cortes del reino, Saragosse, CSIC, 1975, 2 tomes.

${ }^{43}$ Ce point a été souligné par Ralph GIESEY, op. cit., p. 73 et Jesús MORALES ARRIZABALAGA, op. cit., p. $143-144$
} 
Sophie HIREL-WOUTS, « Le Justicia dans quelques chroniques de la Couronne d'Aragon » dans Carlos HEUSCH et Georges MARTIN (dir.), Cahiers d'études hispaniques médiévales, 29, Lyon, ENS Éditions, 2006, p. 277-300.

Justicia sur le roi, rappelant qu'il « est de l'avis de certains qu'ils élurent le Justicia avant le roi », se réclamant d'une autorité dont on ne garde pourtant aucune trace écrite ${ }^{44}$. L'hypothèse d'une version orale du mythe du Justicia est dès lors envisageable, mais aucune preuve n'a pu être établie sur ce point. Les fonctions du magistrat et la nature d'une charge accordée jusqu'alors par le roi - mais qui sept ans plus tard passait aux mains de la noblesse - faisaient à l'époque de Cerdán sûrement parler d'elles, et les propos tenus par notre audacieux Cerdán font état d'une figure du Justicia hautement politisée. Cette lettre a été très diversement appréciée par la critique moderne : tandis que certains se refusent à lui accorder un fondement de vérité, n'y voyant qu'un pamphlet d'auto-exaltation de la part d'un Justicia dont la gestion de la charge a laissé à désirer, d'autres y voient la " première protestation explicite, quoique subtile et chargée d'ironie » d'un homme fier d'avoir exercé cette charge durant trente ans et peu confiant dans les capacités de son successeur ${ }^{45}$. Sans que nous puissions trancher sur la valeur de ce témoignage, il nous faut souligner qu'on y trouve tout ce qui sera le discours d'usage au $\mathrm{XVI}^{\mathrm{e}}$ siècle.

De façon quelque peu paradoxale, c'est une chronique valencienne qui fait entrer le Justicia dans la tradition historiographique de la Couronne d'Aragon (alors que la charge, répétons-le, est strictement aragonaise). Le texte en question, la Chronique anonyme de 1427, a sans doute été rédigé dans la seconde moitié du $\mathrm{XV}^{\mathrm{e}}$ siècle par un noble de l'entourage d'Alphonse $\mathrm{V}$ qui aurait accompagné le roi à Naples avant de revenir à Valence, où il rédige sa chronique. Ici, tout concourt à restreindre le pouvoir royal : le premier roi (Ramire d'Aragon) est choisi par les montagnards non plus parmi les hommes les plus puissants ou les plus vertueux, mais dans une sphère intermédiaire qui garantit aux électeurs une limitation du pouvoir royal. Le pouvoir de ce roi se voit en effet subordonné à des règles rigoureuses, « étroites » (« estrets »), dont le respect est à son tour assuré par le Justicia. « La terre, les chevaliers et les seigneurs, [après s'être] multipliés et revigorés, décidèrent qu'il y ait un roi en Aragon qui ne soit pas choisi parmi les plus grands ni les plus modestes des chevaliers, mais à mi-chemin entre les deux, et qu'il fasse justice et droit aux gens selon certains pactes et privilèges étroits, et s'il ne faisait pas ainsi, que toujours il y ait un Justicia qui le fasse revenir à plus de justice et raison $»^{46}$. Dans cette limitation en cascade des prérogatives du monarque, point de magnificence royale : celui à qui reviennent les vertus de justice et raison (attributs royaux par excellence) est, en dernière instance,

\footnotetext{
${ }^{44}$ Juan JIMÉNEZ CERDÁN, /Letra intimada/, dans Pascual SAVALL Y DRONDA, Fueros, observancias y actos de corte del reino de Aragón, 2 vols., Saragosse, Tipografía Francisco Castro y Bosque, 1866, volume II, p. 81-82. : «... acordaron de esleyr Rey, pero que hoviessen un Iudge entre él e ellos que hoviesse nombre iusticia de Aragon. Es opinion de algunos que antes eslieron al Iusticia que no al Rey e que de aquella condicion lo eslieron".

${ }^{45}$ La première idée est soutenue par Luis GONZÁLEZ ANTÓN, «Alfonso V, las cortes aragonesas y la batalla en torno al justiziazgo ", Estudios sobre Aragón en la Edad media, op.cit., p. 710. La seconde est défendue par Jesús MORALES ARRIZABALAGA, op. cit., p. 137. En fait, les deux critiques défendent deux points de vue opposés sur la relation de dépendance entre le Justicia et la royauté au $\mathrm{XV}^{\mathrm{e}}$ siècle.

${ }^{46}$ Crónica anónima de 1427, fol. 153: «La terra cauallers e senyors muntiplicats e abigorats acordaren que fessen Rey en Arago que no fos dels maiors ni dels menors cauallers mas dels mijans e que fos ab certs pactes e
} 
Sophie HIREL-WOUTS, « Le Justicia dans quelques chroniques de la Couronne d'Aragon » dans Carlos HEUSCH et Georges MARTIN (dir.), Cahiers d'études hispaniques médiévales, 29, Lyon, ENS Éditions, 2006, p. 277-300.

le Justicia. Celui-ci surgit en même temps que la royauté en Aragon (soit en 1060 dans ce texte, au moment de l'élection de Ramire) et fait figure de redresseur de torts face à un roi potentiellement imparfait.

C'est sous un même éclairage que ce motif apparait dans un deuxième texte, catalan cette fois-ci : le Sumari d'Espanya per Berenguer de Puigpardines. Dans un court paragraphe, dont le ton contraste fortement avec l'enthousiasme des Aragonais au moment d'élire leur roi et avec l'exaltation des vertus de ce dernier au paragraphe suivant (chapitre 32 : « il se comportait très bien envers ses vassaux »), la chronique met en scène l'élection du premier Justicia. Le texte est concis mais néanmoins précis sur ce point : employant de nombreux termes juridiques (regidor désigne l'existence institutionnelle du Justicia, fermants de dret les garants du droit), il détaille les raisons qui ont déterminé la nature et les fonctions de la nouvelle magistrature : « il s'ensuit que, voyant l'inexpérience et la jeunesse [du roi] et craignant qu'elles ne soient cause qu'il agisse mal envers l'un d'eux, les nobles voulurent qu'entre le roi et eux il y ait un régisseur auquel ils puissent avoir recours. Pour cette raison, ils choisirent le chevalier qui avait élevé [Sanche Avarca] comme Justicia d'Aragon ${ }^{47}$. De la sorte, si l'un d'entre eux «se sent offensé par [le roi]», tous les nobles - et non pas la seule victime présumée - font appel au Justicia avec l'appui des « autres garants du droit» («fermants de dret ») ${ }^{48} \ldots$ Le Justicia est ainsi clairement défini comme un recours pour la noblesse dans son entier contre le roi et naît dans un climat de méfiance et de tensions entre les nobles et le roi. Dans cette version, le Justicia est identifié, ce qui, à ma connaissance, ne se retrouve dans aucune autre chronique au Moyen Age. Institué lors de l'élection de Sanche Abarca (et non plus Ramire d'Aragon), il n'est autre que le noble qui a sauvé et élevé l'enfant après la mort de la comtesse. L'élection du Justicia n'est plus, comme c'était le cas dans la chronique anonyme de 1427, simultanée à celle du roi, elle lui succède (de peu) et naît de la seule initiative de la noblesse. Rien n'est ici dit d'un magistrat nommé par le roi : est-ce lié au fait que depuis 1442 la charge du Justice se trouve, en vertu d'un for aux arguments historiques douteux, entre les mains de la noblesse et qu'elle est devenue héréditaire dans la famille des Lanuza $?^{49}$ Ce sont en tout cas les nobles qui décident de l'élection d'un Justicia, prétextant la jeunesse du roi (argument fortement appuyé par le doublet «joventut et fadrinea »). En outre, si le chroniqueur prend soin de respecter l'antériorité de la figure royale sur celle du Justicia, ce n'est que de façon relative puisque le magistrat est ici, symboliquement, le père nourricier du jeune roi, père dont la fonction est de redresser les torts («perjuhïns ») de son fils. C'est, dans un premier temps, à titre préventif que la charge est

priuilegis estrets a fer justicia e dret a les gents e si non fahia que tots temps hi hagues hun justicia que li fes tornar les coses a justicia e raho ».

${ }^{47}$ Joan IBORRA, éd., op.cit., p. 177 : « Segui's que los barons, vehent la joventut e fadrinea, tement que no li fahés fer alguna era contra algú d'ells, volgueren que entre lo rey e ells hagués un regidor, al qual poguessen recórrer. E per la dita raó, elegiren lo cavaller que l'havia criat en Justicia de Aragó ».

${ }^{48}$ Ibid., p. 177 : « En manà que si algú d'éls se sentia agreujat d'él, que en tal cas los barons e altres fermants de dret poguessen recórrer al Justicia de Aragó, e aquell agués a conéxer entre ells ».

${ }^{49}$ Voir l'étude de ce for par Luis GONZÁLEZ ANTÓN, « Alfonso V, las Cortes aragonesas y la batalla en torno al justiziazgo », op. cit., p. 712-713. 
Sophie HIREL-WOUTS, « Le Justicia dans quelques chroniques de la Couronne d'Aragon » dans Carlos HEUSCH et Georges MARTIN (dir.), Cahiers d'études hispaniques médiévales, 29, Lyon, ENS Éditions, 2006, p. 277-300.

instituée, comme l'indique l'usage du subjonctif dans la première partie du récit (« auquel ils puissent avoir recours »), mais le ton se radicalise dans le second moment de la narration où sont dénoncés les torts faits à la noblesse : "Et il fut ainsi fait, et depuis ce temps-là il y a un Justicia en Aragon qui a droit de regard sur les préjudices que le roi cause et il les redresse $»^{50}$. Comment ne pas voir dans des "préjudices » causés par le roi une critique cinglante notamment envers Pierre IV, bourreau du mouvement unioniste, que notre chroniqueur - se faisant de nouveau l'écho de Pierre Tomich ${ }^{51}-$ définit par ailleurs comme roi très cruel « car il a fait mourir beaucoup de personnes royales et de gens de son entourage dans un bain de sang $»^{52}$ ? Face aux exactions royales, l'accent est mis sur la continuité ininterrompue d'existence politique du Justicia depuis les temps immémoriaux (le règne de Sanche Abarca) jusqu'à la rédaction de l'œuvre sous le règne de Jean II : le juge entre ainsi en force dans la tradition historiographique. Véritable contre-pouvoir échafaudé par les noblesses de la Couronne d'Aragon afin de restreindre les ambitions du monarque, le mythe est là, de pied en cap.

Deux textes de l'historiographie de l'Orient péninsulaire mettent ainsi en œuvre, dans le troisième quart du $\mathrm{XV}^{\mathrm{e}}$ siècle, un récit du Justicia qui porte sérieusement atteinte à l'intégrité de la figure royale. Les deux premières œuvres à édifier le mythe sont, nous venons de le voir, des textes respectivement valencien (Crónica de 1427) et catalan (Sumari d'Espanya per Berenguer de Puigpardines). Le caractère fortement pro-nobilaire de ces textes n'est certainement pas étranger à l'inclusion du récit du Justicia dans le discours; au-delà de la contestation d'ordre sociopolitique, on peut en effet percevoir à plusieurs reprises dans ces textes, et dans l'émergence même de ce récit, les traces d'une contestation de la part de royaumes chaque fois moins enclins à accepter leur intégration au sein d'une Couronne d'Aragon dont les intérêts éclatent bien souvent. De fait, lorsque la figure du Justicia est reprise par les chroniqueurs du royaume d'Aragon stricto sensu, sa signification change considérablement. Si elle continue à incarner les libertés du royaume, elle fait chaque fois moins ombrage à la représentation du pouvoir royal. Le Justicia ne se dresse bientôt plus contre le roi, il est au contraire un prolongement de ce dernier, l'un et l'autre contribuant à l'équilibre d'un système que l'on veut exemplaire. C'est du moins ce que suggère le nouvel agencement du discours sur le Justicia dans les chroniques du dernier tiers du $X^{\mathrm{e}}$ siècle...

\footnotetext{
${ }^{50}$ Joan IBORRA, éd., op.cit., p. 178, «E axí fou fet, e de aquell temps ençà hi ha Justicia en Aragó que ha a veure sobre los perjuhïns que.ll rey fa e fa.ls tornar a loch ».

${ }^{51}$ Pere TOMICH, op. cit., p. 107 : « per ques pot dir ab veritat quel dit rey fou lo segon Nero en fer morir tantes persones e tant notables acostades al dit rey sens causa ».

52 Joan IBORRA, éd., op .cit., p. 220 : « (aquest rey fou) molt cruel de si, car féu morir moltes persones reals e conjuntes a ell en cincle de sanch ».
} 
Sophie HIREL-WOUTS, « Le Justicia dans quelques chroniques de la Couronne d'Aragon » dans Carlos HEUSCH et Georges MARTIN (dir.), Cahiers d'études hispaniques médiévales, 29, Lyon, ENS Éditions, 2006, p. 277-300.

Lorsque le Generatio rapporte que Navarrais et Aragonais ont élu Iñigo Arista «à condition qu'il leur donne des fors et un juge appelé Justicia d'Aragon et le privilège de l'Union » ${ }^{53}$, il ne sous-entend aucunement que le juge a vocation à redresser les actions du roi, pas plus qu'il ne fait allusion aux torts commis par ce dernier. Le Justicia est certes une condition imposée par le royaume lors de l'élection du roi, mais il n'est plus «élu» au même titre que le roi par le peuple. Dans le plus pur respect de la tradition d'un Justicia nommé par le roi (comme ce fut le cas, de fait, de la naissance de la charge jusqu'en 1442), le texte souligne que l'institution émane de l'autorité royale, laquelle consent à «donner » («daret ») au peuple « des fors et un justice». Dans une atmosphère finement suggérée par le chroniqueur, le Justicia ne se pose alors plus tant comme thème socio-politique que comme horizon idéal ; il forme un couple homogène avec les fors qu'il incarne et est explicitement présenté comme entité aragonaise. La troisième condition imposée - qui fait la particularité de ce texte face aux autres chroniques de la tradition historiographique ${ }^{54}$ - vient quant à elle nier le mouvement historique de l'Union en lui attribuant une lointaine origine légendaire. Cette évolution du rôle du Justicia laisse entrevoir un substrat mental, idéologique et politique bien différent du terreau originel dans lequel le mythe avait germé.

S'inspirant, de l'avis de Jean-Pierre Jardin et Georges Martin, de ce Generatio, la Chronique d'Aragon de Lucio Marineo Siculo atténue encore plus radicalement l'opposition roi-royaume en vigueur dans les premiers témoignages de la légende ${ }^{55}$. Au moment même où il évoque l'élection d'Iñigo Arista, le chroniqueur remémore les « justes lois » que le peuple appelle de ses vœux. Parmi celles-ci se trouve la création de la charge du Justicia : «il fut élu Prince par les Navarrais et Aragonais, après toutefois qu'eurent été posées entre eux quelques conditions au sujet des lois justes avec lesquelles il allait devoir les gouverner. Entre autres conditions, ils demandèrent qu'il y ait un juge médiateur entre eux et le roi et que celui-ci soit appelé le Justicia d'Aragon ${ }^{56}$. L'accent est mis sur rôle de médiateur du Justicia en vue d'un gouvernement plus « juste» du royaume ; la création de ce juge n'est toutefois plus la condition sine qua non au bon gouvernement royal, ni la menace évoquée dans les textes antérieurs; ce n'est qu'une condition parmi d'autres, relativisée par son inclusion dans un contexte plus large. Écrivant au tout début du $\mathrm{XVI}^{\mathrm{e}}$ siècle pour le roi Ferdinand, Marineo Sículo s'interdit de penser une limitation du pouvoir royal et ne reprend - rapidement au

\footnotetext{
${ }^{53}$ Jean-Pierre JARDIN et Georges MARTIN, éd., op .cit., p. 180, concernant l'élection d'Iñigo Arista : «Et Navarrenses atque Aragonenses apud Jucar se in eorum principem eligerunt sub conditione quod daret eis fores et judicem qui vocaretur Justicia Aragonum et privilegium unionis ».

54 Ibid., p. 202: «Dans le cadre d'un jeu d'échos qui demeure, notre sommaire entretient donc avec l'historiographie espagnole orientale des $\mathrm{XV}^{\mathrm{e}}$ et $\mathrm{XVI}^{\mathrm{e}}$ siècles, quant à la légende d'Iñigo Arista, un rapport singulier ».

${ }^{55}$ Ibid., p. 221-222 : « Mais ce fut Marineo Sículo qui, rencontrant notre texte lorsqu'il fouillait à la demande des " députés d'Aragon ", les « archives de Saragosse » (...) l'accueillit avec le plus de sympathie et assura à son contenu la meilleure diffusion $»$.

${ }^{56}$ Lucio MARINEO SICULO, op. cit., fol. VI : « Luego que allí [en Navarra] allegó, fue eligido príncipe por los Navarros y Aragoneses, puestas empero entrellos algunas condiciones a poca de las leyes justas con que los avia
} 
Sophie HIREL-WOUTS, « Le Justicia dans quelques chroniques de la Couronne d'Aragon » dans Carlos HEUSCH et Georges MARTIN (dir.), Cahiers d'études hispaniques médiévales, 29, Lyon, ENS Éditions, 2006, p. 277-300.

demeurant - le motif du Justicia que pour mieux souligner le bien-fondé de l'exercice du pouvoir royal.

Marineo Sículo ne va toutefois pas aussi loin dans son interprétation que le moine de Santa Fe qui, dans son Epilogue des rois d'Aragon ${ }^{57}$, qu'il rédige probablement entre 1461 et 1479, force le trait d'un Justicia pensé et créé par le roi seul (Garci Jiménez), sans qu'aucune condition ne lui soit imposée par ses «électeurs »: «comme un roi qui a de l'amour/ pour la vertu et non la malice/ si jamais il usait de rigueur/ il voulut qu'il y ait un Justicia/ entre le royaume et son seigneur ». Si le roi usait de « rigueur »... Ce terme fait certes écho aux «torts» («perjuhins ») dénoncés dans la chronique dite de 1427 et dans le Sumari d'Espanya per Berenguer de Puigpardines, mais il appartient aussi au vocabulaire juridique de l'époque où il s'oppose à la " miséricorde » du roi, suggérant donc une application stricte du droit comme contraire à la justice. Le juge serait donc là pour juguler toute tentative royale d'application stricte du droit et pour faire appliquer les fors. Vagad revient sur ce thème quelques années plus tard, dès le début de sa Chronique d'Aragon. Les Aragonais réfugiés au monastère de Saint-Jean de la Peña, suivant les conseils des deux bons ermites, «choisirent conjointement et en même temps le magnanime don Garcia Jiménez, Goth royal issu du sang des rois goths, et l'officier qu'ils appelèrent ensuite Justicia d'Aragon comme pour servir d'intermédiaire entre ceux du royaume et leur roi, et entre le roi et ceux du royaume $»^{58}$. Ce choix initial d'un juge intermédiaire est réaffirmé après que le roi a conquis plusieurs terres, légitimant ainsi son titre royal. C'est à ce moment seulement que la double élection est officialisée : le chroniqueur nous informe en effet qu' « en signe de grande reconnaissance », les chrétiens « confirm(ent) de nouveau » et inscrivent dans un «acte public » les deux élections, désormais indissociables dans l'histoire du royaume, «car elles se firent en un même temps et lieu $»^{59}$. L'élection du Justicia a ainsi lieu au moment même de la naissance du royaume de Sobrarbe (avec Garcia Jiménez) : on ne pouvait faire remonter l'institution plus loin ! Légitimée par cette ancienneté, la charge du Justicia l'est aussi par le modèle dont elle est inspirée, celui d'un ancien roi grec et de ses éphores : «[les Aragonais], selon les affirmations de certains, choisirent comme la meilleure forme de gouverner qu'ils trouvèrent celle du roi Théopompe, roi des Spartes, ou roi de Lacédémone, celui même qu'Aristote, dans le cinquième livre des Politiques, loue comme étant la meilleure des polices et des formes de gouvernement qui ont existé en son

de regir. Entrestas pidieron que oviesse un juez medianero entre ellos y el rey y este fuesse llamado el justicia de Aragón. Despues que les ouo otorgado todas estas condiciones penso que armas usaria en sus vanderas ».

${ }^{57}$ Robert Brian TATE, Ensayos sobre la historiografia peninsular del siglo XV, Madrid, Gredos, 1970, p. $263-$ 279 pour l'analyse du texte et p. 304-340 pour sa transcription. Pour le passage qui nous intéresse, concernant l'élection de Garcia Jiménez, voir strophe 41, p. 312 : «Como rey que tiene amor / a virtud y no a maliçia / por si usase de rigor / quizo que huuiese un Justiçia / entre el reino y su señor ».

${ }^{58}$ Gaubert Fabrice de VAGAD, op. cit., fol. III : « escogieron juntamente y de un golpe mismo al magnánimo varón don Garci Ximénez, godo real y de sangre de reyes godos venido, y al official que llamaron después Justicia de Aragón para ser como tercero entre los del reyno y su rey, y entre el rey y los del reyno ».

${ }^{59}$ Ibid., fol. VII : « y luego por esso en señal de mayor agradescimiento confirmaron de nueuo y por abto público mandaron poner la común acordada, tan solempne y justa elección que d'él hauían fecho, y juntamente con ella la elección del Justicia del reyno. Porque en el mismo lugar y tiempo se fizo ». 
Sophie HIREL-WOUTS, « Le Justicia dans quelques chroniques de la Couronne d'Aragon » dans Carlos HEUSCH et Georges MARTIN (dir.), Cahiers d'études hispaniques médiévales, 29, Lyon, ENS Éditions, 2006, p. 277-300.

temps ${ }^{60}$. A cet endroit, à n'en pas douter, Vagad puise abondamment dans la Carta Intimada de Jiménez Cerdán. Tout comme l'ex-Justicia, il présente, "suivant l'opinion des anciens », les chrétiens débattant des avantages et des inconvénients de se soumettre à un souverain et s'inspirant de l'exemple du roi Théopompe pour élire " un roi, mais aussi un juge entre lui et eux, qui s'appellerait Justicia d'Aragon ». L'exemple cependant illustre une situation distincte: s'agissant de Théopompe, on se trouve face à un roi qui avait commencé à régner de façon libre et en seigneur absolu et qui a de son propre chef décider d'autolimiter son pouvoir. L'exemple élargit donc le champ d'action du roi et signifie que quand bien même le roi serait antérieur aux lois, il pourrait avoir décidé de changer son mode habituel de gouvernement afin de s'assurer un règne plus stable et plus pacifique ${ }^{61}$. Ainsi, audelà de leurs divergences, les deux situations évoquées tendent vers une même conclusion : que la royauté et l'institution du Justicia soient concomitantes ou que le roi donne lui-même la possibilité au royaume de choisir ses lois, dans une décision plus personnelle visant à assurer la paix de son royaume, l'union entre le roi et le Justicia est volontaire et harmonieuse et vise à l'équilibre et au bienêtre du royaume tout entier. Enfin, s'il reprend sur ce point le texte de Jean Jiménez Cerdán, Vagad le pousse toutefois dans ses ultimes retranchements, car là où l'auteur de la Carta Intimada proclame que le Justicia a été institué lors de l'élection «du premier roi », sans mentionner ce dernier, notre chroniqueur décrète que puisque Garcia Jiménez a été le premier roi, le Justicia n'a pu être institué qu'aux origines mêmes de la constitution du royaume. Enfin, et cette fois-ci en totale opposition avec les intentions de Jiménez Cerdán, Vagad prend soin de réfuter tout discours suggérant que la charge ne servirait qu'à contraindre le pouvoir royal. Ainsi encense-t-il Jacques II le Pacifique, qu'il nomme roi de Sagesse, qui a su enterrer («sepultar y borrar ») l'Union et tirer avantage de l'institution du Justicia $^{62}$. Il désolidarise de la sorte explicitement le Justicia de l'Union, soulignant combien leurs intentions sont discordantes : le premier est adjuvant du roi, l'autre lui est contraire. De la même façon, il dissocie le juge et le privilège de l'Union dans le temps, n'évoquant une possible destitution $\mathrm{du}$ roi (clause que l'on retrouve dans le privilège de l'Union) que lors du règne d'Iñigo Arista, comme

\footnotetext{
${ }^{60}$ Loc. cit. : « y auido su discreto, común y maduro consejo escogieron, según algunos afirman, por la mejor forma [de] regir que fallaron la del rey Theoponpo, rey de los Spartanos, o rey de Lacedemonia, que aquél mismo es que el Aristótiles al quinto libro de las Políticas loa por la mejor de todas las poliçías y formas de regir que a su tiempo más luzían ». On lit en effet dans ARISTOTE, Politiques, Paris, Flammarion, 1990, livre V, 11 , p. 396 : « C'est pour cela que la royauté dura longtemps parmi les Molosses, et aussi celle des Lacédémoniens du fait que dès l'origine le pouvoir < royal y> fut divisé en deux parties, et qu'ensuite Théopompe, l'ayant limité par divers moyens notamment en instituant au-dessus de lui la magistrature des éphores, en lui enlevant de la puissance accrut la durée de la royauté, de la sorte que d'une certaine manière il la rendit non pas moins mais plus grande ».

${ }^{61}$ L'implication ultime serait alors que le retour d'un roi aragonais aux thèses absolutistes le priverait de stabilité, comme le souligne Jesús MORALES ARRIZABALAGA, op. cit., p. 142.

${ }^{62}$ Fabrice Gaubert de VAGAD, op.cit., fol. CXXXI : «O sapiencia sobrada de rey, que del officio del justicia de Aragón, que pareçe ser puesto para atar las manos al rey y fazer los vasallos esentos, él fizó atamiento, más : cadena, que es más para encadenar sus vasallos y esención para el rey; del officio que fue inventado para se defender los vasallos del rey, él fizó su escudo y defensa para se defender de sus movidos vasallos y regla y ley para los condenar, por las mismas sus libertades como solían convenir los vasallos al rey delante el Justicia para reparar los agravios y restituyr las libertades en pie ».
} 
Sophie HIREL-WOUTS, « Le Justicia dans quelques chroniques de la Couronne d'Aragon » dans Carlos HEUSCH et Georges MARTIN (dir.), Cahiers d'études hispaniques médiévales, 29, Lyon, ENS Éditions, 2006, p. 277-300.

pour ne pas souiller la figure exemplaire du Justicia. Cela lui permet en outre de mieux faire ressortir l'inébranlable loyauté des Aragonais. En effet, juste avant l'élection d'Iñigo Arista, Vagad, omettant toute référence au Justicia, montre que les nobles rassemblés ont décidé que leur nouveau roi devait «jurer les privilèges, fors et libertés du royaume » et souligne que la clause est ratifiée par le nouveau roi qui offre alors à ses sujets la possibilité de le démettre de ses fonctions s'il venait à mal les gouverner... « Le très illustre roi don Iñigo Arista fut ensuite heureux de leur accorder tout ce qu'ils demandaient, et pour les encourager encore davantage, il leur donna pouvoir et licence de choisir un nouveau roi, et même païen si un chrétien venait à manquer, dans le cas où il offenserait ou briserait ce qu'il avant promis. Cela, bien qu'il le leur ait accordé, les Aragonais ne purent le recevoir, car ils ne considéraient pas comme bon de choisir un roi païen $)^{63}$.

Cette clause du Privilège de l'Union, mentionnée pour être mieux rejetée, souligne avec force le caractère sacro-saint du serment royal. Violer le serment est, de l'aveu même du roi, motif de destitution. Le refus de l'absolutisme prime dans tout ce passage. Il est, de fait, omniprésent dans la chronique vagadienne et prend les allures d'une véritable proclamation d'idéologie politique. Déjà Garcia Jiménez affirme qu'il ne lui agrée pas de se comporter en roi « absolu » ${ }^{64}$, et les Aragonais euxmêmes, lors de l'élection d'Iñigo Arista, manifestent leur aversion pour ce type de pouvoir ${ }^{65}$. Dans cette deuxième étape, celle de la consolidation du mythe, le Justicia apparaît donc davantage comme symbole d'un refus de l'absolutisme que comme force d'opposition face au pouvoir royal. Dans l'écheveau idéologique et politique qu'est la Couronne d'Aragon à la fin du Moyen Age, où les solidarités et les affrontements se développent à différentes échelles, il est difficile d'attribuer une explication unique à la fixation par écrit du Justicia comme symbole d'un système pactiste exemplaire. Tout laisse à penser cependant qu'au moment de l'union dynastique des royaumes de Castille et d'Aragon, il s'est avéré urgent de réaffirmer la spécificité aragonaise, de montrer l'excellence d'un système rétif à tout autoritarisme.

Annoncé par une série d'indices auxquels il sera par la suite intimement associé - l'émergence d'un royaume de Sobrarbe, l'affirmation de théories pactistes - le Justicia fait l'objet, dans la seconde moitié du $\mathrm{XV}^{\mathrm{e}}$ siècle d'un récit à l'armature narrative puissamment élaborée qui assurera la postérité

\footnotetext{
${ }^{63}$ Ibid., fol. XVII : « Fue luego mucho contento el esclareçido rey don Yñigo Arista de les otorgar quanto pidían, y ahún por los más animar les otorgó poder y licencia de escoger nueuo rey, y ahún pagano si cristiano falleçía, do caso que los él agrauiesse o quebrantasse lo prometido. Esto, bien que lo otorgasse, los aragoneses no lo recibieron, assí que escoger rey pagano en algún caso no lo tenían por bueno ».

${ }^{64}$ Ibid. Garcia Jiménez emploie les termes suivants, fol. VI : "Otras muchas razones me ocurren, dixo el magnánimo rey, que fazen mi derecho más valedero y constante, que dexo agora por breue ser, no que me plega por esso de presumir nin mucho de señor, ni de príncipe, ni de rey absoluto, ni que la virtud tal me consienta ni cabe en mi condición y desseo el desconocer los que soys».

${ }^{65} \mathrm{Ibid}$., fol. XVI : « [los fueros] le fueron primero leýdos delante y protestado y fecho saber que no le recebían como a Rey absoluto que puede (como se le antoja) mandar y regir ... ».
} 
Sophie HIREL-WOUTS, « Le Justicia dans quelques chroniques de la Couronne d'Aragon » dans Carlos HEUSCH et Georges MARTIN (dir.), Cahiers d'études hispaniques médiévales, 29, Lyon, ENS

Éditions, 2006, p. 277-300.

$\mathrm{du}$ mythe et son triomphe au siècle suivant. Les agencements textuels et les circulations internes de cette narration laissent entrevoir les divers substrats idéologiques et politiques qui ont présidé à sa composition. Ce récit, qui vit de ses propres variantes, porte en effet la marque de tactiques et de désirs contradictoires : d'emblée intégré au projet idéologique d'oligarchies qui n'aspirent qu'à contraindre l'exercice du pouvoir royal, il est sitôt «détourné » et invoqué comme symbole d'une identité aragonaise stricto sensu pour servir un aragonisme chaque fois plus impérieux. 